\title{
A força dos dispositivos*
}

Nicolas Dodier

\& Janine Barbot**

Resumo: As ciências sociais podem se beneficiar de uma atenção particular ao lugar que ocupam os dispositivos na vida social. O interesse de uma tal perspectiva reflete-se nas pesquisas que, desde o final dos anos 1970, recorreram a essa noção. Mas a leitura desses trabalhos mostra igualmente, além da grande variedade de definições e objetivos associados ao conceito de dispositivo, certas dificuldades encontradas pelo caminho. Ela estimula um esforço de clarificação e renovação, tanto no plano conceitual como metodológico, contribuição procurada por este trabalho. Na primeira parte do artigo, apresentaremos os resultados de um levantamento conceitual sobre a noção de dispositivo. Na segunda parte, desenvolveremos uma série de proposições que visam elaborar uma abordagem "processual" dos dispositivos. Retomamos diversas pesquisas que conduzimos nessa perspectiva em torno de dispositivos de reparação: estudo do trabalho doutrinal de juristas em torno do processo penal, práticas dos advogados na audiência de um processo, reações de vítimas de uma catástrofe sanitária face a um fundo de indenização, transformações históricas de dispositivos de reparação de erros médicos desde o início do século XX.

Palavras-chave: dispositivos, teoria sociológica, pragmatismo francês.

A s ciências sociais podem se beneficiar de uma atenção particular conferida ao lugar que os dispositivos ocupam na vida social. O interesse de uma tal perspectiva reflete-se no exame de pesquisas que, desde o final dos anos 1970, recorrem a esta noção ${ }^{1}$. A leitura desses trabalhos mostra igualmente, além da grande variedade de definições e de objetivos associados ao conceito de dispositivo, certas dificuldades encontradas pelo caminho. Incita a um esforço de clarificação e de renovação tanto sobre o plano conceitual como metodológico, contribuição à qual o presente artigo pretende participar.

Em nossos trabalhos, esta clarificação apresentou-se em várias etapas. Por um longo tempo, como foi o caso de diversos pesquisadores, fomos afetados pelo lugar que ocupam, na emergência e nas transformações da normatividade, esses assemblages $^{2}$ complexos que são, por exemplo, as cadeias de produção na indústria, as ferramentas mobilizadas nos diagnósticos médicos, ou ainda os testes de medicamentos (Dodier, 1993; 1995; 2003; Barbot, 2002). A noção de dispositivo, então, pareceu-nos uma maneira interessante de abordar esses assemblages. Mais recentemente, ao pesquisarmos sobre a reparação de erros médicos, sentimos a necessidade de fazer uma clarificação conceitual suplementar em razão da variedade de dispositivos aos quais fomos confrontados (Barbot \& Nicolas, 2014a; 2014b; 2015a; 2015b;

\author{
* Os autores \\ agradecem aos \\ participantes \\ do programa \\ interuniversitário \\ Social Studies \\ of Institutions \\ (Washington \\ University in St. \\ Louis, University \\ of Amsterdam, \\ École des Hautes \\ Études em Sciences \\ Sociales), assim \\ como a Michel \\ Grossetti, a Liora \\ Israël e a Christian \\ Licoppe, por seus \\ comentários às \\ primeiras versões \\ deste trabalho. \\ A versão original \\ foi publicada nos \\ Annales HSS, v. 71, n. \\ 2, p. 421-450, Paris, \\ Éditions de l'Ehess, \\ 2016, e sua tradução \\ e publicação na \\ Sociedade e Estado \\ devidamente \\ autorizadas pelos \\ editores. \\ Tradução de Diogo \\ Silva Corrêa, pós- \\ doutorando no \\ Instituto de Estudos \\ Sociais e Políticos \\ da Universidade \\ do Estado do Rio \\ de Janeiro (lesp- \\ Uerj) e Carlos \\ Gutierrez, doutor em \\ antropologia social \\ na Universidade \\ Estadual de \\ Campinas (Unicamp). \\ ** Nicolas Dodier \\ Institut National \\ de la Santé et de la \\ Recherche Médicale, \\ (Inserm), École des \\ Hautes Études em \\ Sciences Sociales
}


(Ehess), Institut

Marcel Mauss/

Centre d'Études des

Mouvements Sociaux;

Janine Barbot,

Institut National

de la Santé et de la

Recherche Médicale,

(Inserm), Institut

Marcel Mauss/

Centre d'Études des

Mouvements Sociaux.

1. Para um primeiro panorama de pesquisas, ver JeanSamuel Beuscart \& Ashveen Peerbaye (2006); Laura SilvaCastañeda (2012).

2. Optamos por não traduzir o termo assemblage, uma vez que já existe o estrangeirismo assemblagem na língua portuguesa, mantendo mesmo seu gênero

masculino da língua francesa. Um sinônimo aproximado seria reunir, ajuntar, agrupar. Na arte, a noção é usada para definir colagens com objetos, por meio da ideia de que tudo pode ser incorporado, criando um novo conjunto sem perder características originais de cada objeto. Alguns exemplos dessa produção artística: Jean Dubuffet, Pablo Picasso, Georges Braque e Robert Rauschenberg (nota dos tradutores).

3. A pesquisa explica os diferentes usos do conceito de dispositivo nos trabalhos das ciências sociais de língua francesa, nos quais os autores
Barbot, 2016). Em matéria de reparação, os processos judiciários, os sistemas de indenização financeira, a imprensa e os suportes de ação coletiva ou associativa são dispositivos que se entrecruzam uns com os outros. Diante desta variedade, a elaboração de uma estratégia geral de análise se impunha. Nós decidimos, então, articular nossas pesquisas numa investigação conceitual sobre a própria noção de dispositivo.

A primeira parte deste artigo apresenta os resultados dessa investigação ${ }^{3}$. As principais propriedades das entidades às quais os autores das ciências sociais se interessaram através da noção de dispositivo são identificadas. A heterogeneidade interna de dispositivos, quer dizer, a variedade de seus componentes, diante das grandes categorias de elementos existentes, é uma propriedade decisiva que merece desenvolvimentos particulares, que concernem tanto ao sentido que convém dar a essa multiplicidade, quanto a suas implicações para o estudo de interações entre humanos e dispositivos. Três outras propriedades desempenham um papel importante no recurso a essa noção: uma relação dual para com os ideais, o fato de os dispositivos preencherem uma finalidade, bem como de desempenharem um poder de transformação com relação aos indivíduos colocados em contato com eles. Uma discussão crítica de trabalhos em torno de cada uma dessas propriedades permitirá precisar os contornos que pode assumir hoje a abordagem dos dispositivos.

A segunda parte desenvolve essas proposições. Trata-se, em primeiro lugar, de formular uma definição de dispositivos que se beneficia dos resultados da investigação conceitual. Na sequência, cabe traçar as grandes linhas de um método de análise cuja principal orientação consiste em trazer à luz os apoios normativos nos quais os indivíduos se assentam para se posicionarem em face dos dispositivos. De fato, ao constatar a amplitude das coerções que os dispositivos exercem sobre os indivíduos, pudemos observar nestes últimos capacidades de avaliação que testemunham uma forma de exterioridade normativa a respeito dos dispositivos. A noção de repertório normativo é introduzida com essa intenção. Por fim, voltaremos de maneira mais detalhada sobre as pesquisas que dizem respeito aos dispositivos de reparação para mostrar o interesse da abordagem proposta e sugerir prolongamentos possíveis.

\section{Agenciamentos heterogêneos}

A emergência da noção de dispositivo está associada à conscientização da importância que possuem, na vida social, certos agenciamentos de elementos heterogêneos que não podem ser reduzidos a nenhuma das grandes categorias de seres sociais geralmente estudados pelas ciências sociais. O recurso a essa noção permitiu ultrapassar algumas das grandes linhas de demarcação. Vários autores mostraram, 
assim, a importância de acrescentar a consideração de objetos "materiais" às análises antes limitadas a entidades comumente declaradas como "sociais": regras, normas, redes, interações, linguagem ${ }^{4}$. Estes autores interessaram-se por assemblages que têm por especificidade associar fortemente duas grandes categorias. Outros autores sublinharam a importância de pensar associações entre humanos e não humanos (Callon, 1986; Latour, 1989). Outros, por fim, optaram por manter uma abertura de princípio à própria natureza das categorias que pode se revelar pertinente para a análise dos assemblages assim constituídos. Pelo emprego de listas resolutamente heteróclitas, os autores apontaram para a necessidade de tornar o olhar do pesquisador atento às particularidades de cada composição 5 .

O apelo à superação dos grandes divisores perdeu parte da tonalidade polêmica de que era dotado nos anos 1980. Mas essa atenção à heterogeneidade permanece uma exigência heurística de método. A partir de uma dada categoria de existentes, esse método incentiva que se tenha atenção às solidariedades estabelecidas com outras categorias de elementos existentes e a pensar os conjuntos assim formados. Ao partir, por exemplo, de uma interrogação sobre o lugar das regras nas práticas sociais, ele incentiva que se tenha interesse nos suportes com base nos quais tais regras se tornam disponíveis para os atores: softwares, telas, textos, listas etc. Um objeto de investigação tal como o processo judiciário, pensado inicialmente em termos de procedimento, torna-se igualmente, desde quando examinado como dispositivo, um agenciamento que integra objetos técnicos, espaço, mobílias, prédios etc. Ao interrogar-se sobre o lugar dos objetos, a análise feita pelos dispositivos evidencia o conjunto de regras, de palavras ou de enunciados aos quais esses objetos estão relacionados e através dos quais eles exercem uma influência sobre as condutas dos atores.

Essa atenção voltada para os agenciamentos heterogêneos induz deslocamentos no trato com uma questão central para as ciências sociais: o exercício da coerção. Porque ela integra a consideração de elementos materiais, e abre o olhar para o papel dos objetos. O exercício da coerção conduz a pensar a respeito da variedade de intermediários e de modos pelos quais cada um desses objetos guia a atividade (Conein et alii, 1993). Porque a variedade de intermediários convida a que se pense para além de cada objeto, graças à noção de dispositivos, conjuntos mais amplos de elementos, ela permite ver em que medida essa coerção se encontra distribuída entre diversos componentes. O pesquisador, então, percebe melhor as consequências para os seres humanos do fato de se encontrarem confrontados a tais conjuntos, ao invés de tal ou tal outro elemento de coerção considerado pontualmente. Quando um objeto, uma regra ou um princípio se impõe a um indivíduo, o observador, armado do conceito de dispositivo, pode examinar em que conceitualizam o emprego da palavra.

4. Pode se tratar, por exemplo, de levar em consideração o "não discursivo" (Foucault, 2001: 300-301), os elementos "materiais e maquínicos" (Naepels, 2012: 91), os "objetos", no sentido de objetos materiais (Boltanski \& Thévenot, 1991: 20), os "dispositivos materiais" (Callon \& Muniesa, 2003: 189-233), as "tecnologias" (Weller, 2003: 251), ou ainda a "técnica" - medida, cálculo, regra jurídica, procedimento - em suas relações com o "social" (Lascoumes \& Le Galès, 2004: 21).

5. Pode-se lembrar essa fórmula frequentemente citada de Michel Foucault (2001: 299): “O que eu tento localizar sob esse nome é, primeiramente, um conjunto efetivamente heterogêneo que comporta discursos, instituições, organizações arquitetônicas, decisões regulamentares, leis, medidas administrativas, enunciados científicos, proposições filosóficas, morais, filantrópicas. Em suma: o dito assim como o não dito, eis os elementos do dispositivo". 
6. Ver, por exemplo, como Jacques Ion e Bertrand Ravon (2005) unificam em torno do termo dispositivo as novas formas de intervenção que foram desenvolvidas no trabalho social na França a partir dos anos 1980. e até que ponto esse componente é, na realidade, sustentado pelo conjunto de outros ingredientes dos dispositivos aos quais ele mostra-se solidário. A noção de dispositivo carrega em si mesma uma dupla exigência de método: de um lado, a decomposição analítica paciente dos ingredientes assim mobilizados; de outro, a atenção dada à consistência do agenciamento global pelo qual se exerce a coerção.

É igualmente um dos interesses da noção de dispositivo permitir pensar graus de coerção variáveis (Peeters \& Charlier, 1999). Em um dos polos, é possível dar conta de coerções extremas. Os trabalhos de Michel Foucault (1975) sobre as disciplinas vão nesta direção. Mas a noção de dispositivo foi mobilizada para descrever, no outro polo, formas de condução particularmente maleáveis. Uma parte dos trabalhos das ciências sociais utilizará a noção a partir desta perspectiva ${ }^{6}$. As palavras direcionamento, concertação, horizontalidade, localidade, personalização tornam-se centrais para qualificar esse tipo de intervenção. A noção de dispositivo é empregada nesses trabalhos para pensar em que essas formas de condução se distinguem das modalidades mais tradicionais de enquadramento. Uma definição ampla da noção de dispositivo deveria permitir abordar o conjunto do espectro.

\section{As interações entre os humanos e os dispositivos}

Essa heterogeneidade interna produz problemas específicos a partir do momento em que se trata de estudar as interações entre indivíduos e dispositivos. Como construir uma descrição que possa dar conta de mediações cuja variedade parece permanentemente transbordar a linguagem das ciências sociais? Várias estratégias foram propostas para responder a essa questão. Dentre elas, duas podem ser lembradas.

A primeira estratégia proposta pelos defensores da teoria do ator-rede repousa sobre uma abertura de princípio no que concerne ao conjunto de mediações. Ela visa integrar nas narrativas de inovação técnica ou científica a multidão, a imprevisibilidade e irredutibilidade das "forças" de toda natureza que intervêm nesses processos (Latour, 1984). Esta ampliação da atenção para o conjunto de mediações entre indivíduos e dispositivos conduziu as ciências sociais na direção de formas de descrição inéditas. Contudo, pode-se questionar a respeito da capacidade do pesquisador, fazendo tudo o que está ao seu alcance para seguir o conjunto de "actantes" - humanos e não humanos - engajados nessas histórias. Do mesmo modo, pode-se sublinhar a dificuldade de manutenção das narrativas nas quais se mesclam constantemente considerações sobre os próprios actantes e sobre a linguagem que os humanos utilizam para falar desses actantes. Pela clareza da análise, uma distinção entre esses dois níveis de descrição deveria ser mantida. 
A segunda estratégia, realizada por diferentes correntes, consiste em estender progressivamente o nível de análise. O pesquisador parte das mediações entre os indivíduos e os dispositivos, que são habituais em ciências sociais: categorias, convenções, regras, representações, esquemas etc. Em seguida, ele amplia o estudo dessas interações para níveis de análise que são perceptíveis tão somente através de métodos complementares de observação, geralmente mais detalhados. Ele articula, assim, no primeiro nível de análise, a consideração de elementos de "familiaridade" (Thévenot, 1994; 2006) ou de "preensões" (prises) (Bessy \& Chateauraynaud, 1995), pelos quais os indivíduos abordam os dispositivos. Leva em consideração operações linguísticas bastante indexadas (Suchman, 1987; Fornel \& Verdier, 2014); associa sua análise ao estudo de gestos e de movimentos perceptivos (Licoppe, 2008); integra à sua análise a consideração de "affordances" (Gibson, 1979). Essa estratégia abriu novas pistas de exploração para as ciências sociais, por vezes em associação com outras disciplinas tais como a linguística, a psicologia cognitiva ou a ergonomia. Uma dificuldade pode residir, contudo, em sua capacidade de articular entre as disciplinas níveis de análise que, em razão de sua própria variedade, correm o risco de resistir às tentativas de integração.

Para dar conta dos dispositivos, as ciências sociais devem, portanto, encontrar fórmulas que permitam conjugar tudo ao mesmo tempo, a saber, a abertura à heterogeneidade interna dos agenciamentos considerados e a delimitação de um nível de análise que as ciências sociais podem estudar com uma capacidade de integração suficiente. As duas estratégias precedentes compartilham a mesma vontade de estender a natureza das mediações para as quais as ciências sociais se consideram competentes. Mas elas colocam uma questão quanto ao nível de análise visado. Esse artigo desenvolve uma terceira estratégia que se concentra sobre uma das mediações por meio da qual dispositivos e humanos interagem: o trabalho normativo dos indivíduos em torno desses dispositivos. Por trabalho normativo, designamos, de maneira geral, as avaliações, positivas ou negativas, que os indivíduos sustentam de modo explícito sobre os estados de coisas. Este trabalho é concebido como normativo no sentido amplo. Com efeito, toda avaliação refere-se, necessariamente, ainda que de modo mais ou menos explícito, a expectativas normativas concernentes aos estados de coisas. A abertura à heterogeneidade de agenciamento é mantida, mas ela consiste, desta vez, em seguir os indivíduos quanto aos elementos do dispositivo que eles problematizam e que consideram como pertinentes em suas avaliações. Esta terceira estratégia conjuga, portanto, uma reorientação do domínio de competência das ciências sociais e a manutenção de uma atenção à heterogeneidade interna dos agenciamentos com os quais os indivíduos são confrontados. Através desta reorientação do trabalho normativo, perde-se as formas de abertura que as ciências sociais puderam desenvolver na análise dos dispositivos. Ganha-se, 
7. Agradecemos a Christian Licoppe pela sugestão dessa noção.

8. O termo "ideais" é empregado para fazer referência aos objetivos que são, ao mesmo tempo, valorizados e de alcance geral. Esses objetivos podem ganhar a forma de valores, modelos, princípios, de universais etc. Os diferentes modos de expressão de ideais devem ser, por vezes, cuidadosamente discernidos e podem ser reunidos sob o mesmo termo quando se examina essa segunda propriedades dos dispositivos. por outro lado, a possibilidade de apreender de maneira mais completa e mais esquematizada o modo como se estruturam as bases normativas a que os indivíduos se referem em sua relação com os dispositivos.

Esse trabalho normativo por parte dos indivíduos pode originar-se a partir de duas formas de orientação reflexiva ${ }^{7}$. Ele pode referir-se ao próprio dispositivo: nesse caso, os indivíduos se posicionam a respeito da maneira como esse lhes parece ou não ajustado às suas expectativas. É o caso, por exemplo, quando médicos, pessoas que trabalham na indústria ou associações de pacientes avaliam se as tentativas de medicação foram concebidas de modo correto (Dodier, 2003). Esse trabalho normativo pode também concernir às condutas dos indivíduos dentro do quadro de referência de um dispositivo. Este é, então, visto como um dado e os indivíduos julgam como outros indivíduos se conduzem, são conduzidos ou deveriam conduzir-se em relação a esse dispositivo, individual ou coletivamente. É o caso, por exemplo, quando os operários se interpelam uns aos outros quanto à sua habilidade para pôr em funcionamento uma linha de produção (Dodier, 1995). Diferentes aspectos desta linha são então tornados pertinentes nestes julgamentos a respeito da aptidão técnica que possuem: tal ou tal regra pode ser apontada (mesmo que seja para externarem sua capacidade de se distanciarem dela), tal parte do conjunto técnico pode ser destacada (sobre a qual os operários se apoiam, ou, ao contrário, procuram evitar). Segundo os casos, os indivíduos distinguem ou mesclam essas duas formas de orientação reflexiva: uma que reflete "sobre o dispositivo" e outra que se volta para pensar "no dispositivo".

\section{As outras propriedades dos dispositivos}

Se essa atenção à heterogeneidade interna dos agenciamentos que contribuem à vida social foi um recurso central em certas reorganizações conceituais das ciências sociais nos últimos 40 anos, ela não foi a única propriedade atribuída aos dispositivos. Três outras podem ser examinadas.

\section{Uma relação dual para com os ideais}

Os questionamentos sobre as relações que os indivíduos entretêm com os ideais desempenharam um papel importante no interesse pela noção de dispositivo ${ }^{8}$. Eles começam com duas opções. Na primeira, autores como Laurent Thévenot (1986: 71-72) e Luc Boltanski (Boltanski \& Thévenot, 1991: 20) insistiram sobre o fato de que os dispositivos veiculam ideais e contribuem, assim, para influenciar as práticas. Seus trabalhos mostraram como os dispositivos equipam os objetos para que sejam capazes de carregar em si mesmos a "generalidade". Outros autores 
deslocaram a abordagem da ação pública em direção ao estudo dos "instrumentos", evidenciando em que medida estes são "portadores de valores, nutridos por uma interpretação do social e por concepções precisas do modo de regulação buscado" (Lascoumes \& Le Galès, 2004: 13). Na segunda opção, os autores insistiram sobre a imanência das práticas assim produzidas. Esse aspecto é central na atenção que confere Gilles Deleuze (1989) à noção de dispositivo de Foucault. Mais do que se interessar pelos universais, Deleuze privilegia o estudo de "processos imanentes". Segundo ele, "objeto", "sujeito", "totalidade", "verdade" são "processos singulares de unificação, de totalização, de verificação, de objetivação, de subjetivação imanentes a tal dispositivo" (Deleuze, 1989: 188). A mesma perspectiva é desenvolvida por Michel Callon e Fabien Muniesa a respeito dos "dispositivos de cálculo" que tornam possíveis "cálculos complicados que produzem soluções práticas de problemas que nenhuma modelização teórica permitiria resolver" (Callon \& Muniesa, 2003: 191).

Essas duas opções sobre a relação dos dispositivos com os ideais sublinham diferentes características dos dispositivos. A primeira opção torna o observador sensível ao que, nos dispositivos, procede de uma referência endógena aos ideais. Enunciados, palavras ou símbolos que são parte integrante dos dispositivos fazem explicitamente referência a esses ideais. É igualmente o caso dos elementos que acompanham estes dispositivos: guias de uso, preâmbulos, instruções, comentários, remissões a outros textos etc. Se mobilizada sozinha, contudo, essa opção corre o risco de conduzir o observador a interpretar abusivamente certos índices como referências a ideais ou a presumir que todo dispositivo apresenta essa capacidade de transportar ideais. A segunda opção dá conta do fato de que os objetos aos quais fazem referência os enunciados, as palavras ou os símbolos associados aos dispositivos podem remeter a qualquer outra coisa além de ideais. Assim, quando se observa uma cadeia de produção, é-se afetado por uma variedade de elementos que se comportam como "instâncias normativas" (Dodier, 1995) para o operador: pressões físicas, pontos de referência cognitivos, palavras que se afixam, injunções verbais ou consignações escritas transmitidas por outros humanos. Entretanto, os objetivos visados não são sempre claros ou, quando o são, não são necessariamente assimiláveis a ideais. Nessas situações, os próprios indivíduos desenvolvem em torno do dispositivo um trabalho normativo a partir de avaliações - positivas ou negativas - a serem formuladas em relação aos ideais.

Mais do que separar uma ou outra dessas opções, propomo-nos assumir a variedade de relações que os elementos dos dispositivos entretêm, enquanto instâncias normativas, com os ideais. No curso da análise, trata-se de articular, de um lado, a atenção ao que, nos dispositivos, é da ordem de uma referência endógena aos 
9. Poder se acordar entre atores

(Eymard-Duvernay \& Marchal, 1994,

p. 10); limitar

as relações de

força (Boltanski \& Chiapello, 1999:

466); reunir os elementos de prova (Chateauraynaud, 2004); assegurar a função durável do mercado (Karpik, 1989).

10. Permitir a "inspeção do olhar" mediante "dispositivos de inscrição" (Latour, 1985); produzir as "forças" que vão sustentar uma inovação científica ou técnica, por meio de "dispositivos de participação" (Akrich et alii, 1988); "manter presentes os seres cuja justificação suporia a ascensão em generalidade em mundos diferentes" (Boltanski \& Thévenot, 1991: 33).

11. Essa é a crítica que endereçamos à "linguagem de ordem" nas ciências sociais, caracterizada de maneira geral pela preocupação de avaliar como e até que ponto as práticas dos atores contribuem para uma certa ordem social. (Dodier, 2014). objetivos visados; de outro, a atenção ao trabalho pelo qual indivíduos vinculam os objetivos visados aos dispositivos.

\section{Entidades depositárias de finalidades}

Nas ciências sociais, diversos trabalhos recorreram à noção de dispositivo para registrar a importância na vida social de agenciamentos aos quais pode-se atribuir finalidades. Estes foram abordados segundo duas abordagens principais.

Pesquisadores desenvolveram uma abordagem dos dispositivos que se pode qualificar de funcional. Segundo esses autores, a existência de dispositivos, e a forma que eles assumem, podem ser explicados pelo fato de que os humanos devem realizar, graças aos próprios dispositivos, operações necessárias à vida em sociedade. Finalidades são assim consideradas como consubstanciais aos dispositivos. Elas revelam a "necessidade" e permitem distinguir os dispositivos uns dos outros. A evidenciação dessas finalidades é considerada como um desafio maior das ciências sociais. Esta abordagem funcional de dispositivos mostra-se interessante por duas razões. Primeiro ela mostrou, por funções clássicas, o papel que desempenham esses agenciamentos heterogêneos ${ }^{9}$. Permitiu igualmente sublinhar as exigências da vida social sobre as quais as ciências sociais tinham até então dado pouca atenção ${ }^{10}$. No entanto essa abordagem apresenta uma dificuldade. O pesquisador concede, do exterior, uma finalidade ao dispositivo, do qual ele estabelece, de algum modo, a sua razão de ser. Ora, os próprios atores atribuem finalidades aos dispositivos, sejam eles os próprios idealizadores do dispositivo, aqueles que o colocam para funcionar ou o próprio alvo do dispositivo. Preso à abordagem funcional, o pesquisador corre o risco de avaliar o dispositivo unicamente sob o critério da função que ele the atribuiu e de considerar como secundária a complexidade do trabalho normativo por meio do qual os atores atribuem finalidades variadas ou mutáveis, por vezes imprevisíveis, a esses dispositivos. Em certos casos, é em nome da revelação da "verdadeira" função de um dispositivo que os pesquisadores defendem que os atores se enganam em meio às relações que eles entretêm com esse último ${ }^{11}$.

As finalidades dos dispositivos foram igualmente desenvolvidas por uma segunda abordagem, que se pode qualificar de crítico-estratégica. Essa abordagem retém da análise estratégica, no sentido amplo, uma atenção voltada para a elucidação dos motivos que os indivíduos apresentam para agir. Ela dirige seu foco, contudo, para os motivos que parecem problemáticos ao pesquisador. Segundo essa abordagem, os atores se servem dos dispositivos para alcançarem objetivos ao mesmo tempo escondidos (pois esses se afastam dos ideais que são afixados) e primeiros (pois 
esses objetivos são supostos desempenhar um papel essencial na existência e na aparência dos dispositivos). Foucault expõe, nesses termos, a ideia de uma "função estratégica dominante" vinculada a cada dispositivo:

Eu disse que o dispositivo era de natureza essencialmente estratégica, o que supõe que se trata aí de uma certa manipulação de relações de forças, de uma intervenção racional e concertada nas relações de força, seja para desenvolvê-las em uma tal direção, seja para bloqueá-las, ou para estabilizá-las, utilizá-las (Foucault, 2001: 300).

Essa "manipulação de relações de forças" se exerce por vezes de cima a baixo, mas ela é modelada geralmente em níveis e segundo direções variadas, de tal modo que nenhum ator pode ser declarado como o idealizador dessa estratégia. Trata-se sobretudo de uma "necessidade estratégica" que se impõe aos atores (Foucault, 2001: 309) e que explica a formação e as transformações do dispositivo. Ora, essa abordagem apresenta um inconveniente do mesmo gênero que a abordagem funcional, ainda que por razões diferentes. Ela corre o risco de considerar como epifenômenos as finalidades que os atores atribuem explicitamente aos dispositivos com relação à necessidade estratégica que o sociólogo se considera capaz de revelar ${ }^{12}$

Para evitar as dificuldades próprias a essas duas abordagens, optamos por uma abordagem atributiva de finalidades. Esta repousa, portanto, sobre o estudo do modo como os atores atribuem finalidades aos dispositivos, sem decidir de antemão aquelas mais essenciais a que os dispositivos supostamente deveriam preencher. Essa abordagem pode apoiar-se sobre dois tipos de dados. De um lado, pode interessar-se pelas finalidades às quais certos elementos de dispositivos podem eles próprios fazer referência de modo endógeno. De outra parte, pode apoiar-se no estudo do trabalho normativo dos atores em torno dos dispositivos.

\section{O poder de transformação associado aos dispositivos}

As ciências sociais sublinharam uma última propriedade dos dispositivos: seu impacto transformador. Essa dimensão de fabricação, de produção, de criação é central na defesa da noção. Ela foi considerada a partir de diferentes direções: para mostrar a contribuição particular dos dispositivos para a produção de novos "saberes" (Favereau, 1989), para evidenciar o deslocamento das demarcações entre visibilidade e invisibilidade (Deleuze, 1989; Naepels, 2012; Karpik, 1996: 538-539), para fazer valer o estabelecimento de novas realidades convencionais (Desrosières, 1993; Lascoumes \& Le Galès, 2004), ou ainda para descrever a produção de novas competências dos indivíduos (Gomart \& Hennion, 1999). Essa consideração do impacto transformador dos dispositivos apresenta vantagens fundamentais para as

12. Há um limite nos trabalhos que revelam de uma maneira geral a "linguagem da força", caracterizada pela preocupação em remeter as ações humanas às forças sociais subjacentes, que afastam os atores dos ideais ou dos valores que eles se dão ou a que eles dão prioridade. Ver Nicolas Dodier (2014). 
ciências sociais, pois evidencia um poder de transformação ao mesmo tempo do ambiente dos indivíduos, das modalidades por intermédio das quais esses últimos apreendem esse ambiente, de suas capacidades de intervenção sobre este e, em certa medida, sobre os próprios indivíduos. Ela mostra que os dispositivos devem ser pensados simultaneamente sob o ângulo das coerções que eles exercem e dos suportes que podem oferecer aos indivíduos para agir.

\section{Uma abordagem processual dos dispositivos}

A partir dessas discussões, é agora possível precisar nossa definição da noção de dispositivo no quadro de uma abordagem processual, e de voltar a atenção para as linhas de pesquisa inerentes a essa abordagem. A questão da tradução dessa noção nos trabalhos de língua inglesa também será abordada.

De maneira geral, um dispositivo pode ser concebido como um encadeamento preparado de sequências, destinado a qualificar ou a transformar estados de coisas por intermédio de um agenciamento de elementos materiais e linguísticos. Essa definição mantém a propriedade da heterogeneidade no núcleo da noção. Ela acentua as categorias do material e do linguístico. Não se trata aqui de indicar uma grande divisão ontológica, mas de apontar, desde um plano metodológico, a variedade de direções em torno das quais pode orientar-se o trabalho de descrição. Todos os tipos de componentes podem aparecer entre os elementos materiais em questão, sem que seja necessário fixar a priori a lista de componentes. Os próprios componentes linguísticos podem ser variados: escritos e orais, narrativos e não narrativos etc. Eles podem mesmo fazer referência a todo tipo de entidades, à medida das capacidades de invenção idiomática dos humanos.

A noção de encadeamento de sequências acentua uma dimensão que não está suficientemente presente nas abordagens existentes acerca dos dispositivos: a extensão temporal de sua realização. Pode-se falar, por essa razão, de uma abordagem processual de dispositivos. É porque há um agenciamento - e, portanto, uma solidariedade frouxa e intangível - entre os elementos, que um encadeamento de sequências já está potencialmente sempre presente. Os indivíduos podem lidar com esse encadeamento como coerção ou podem nele se apoiar. Essa solidariedade de elementos no seio de um agenciamento resulta de uma história anterior. Dizer que o agenciamento "prepara" o encadeamento é dar-se os meios para pensar graus de coerção variáveis, desde uma sucessão praticamente imparável de etapas até uma multidão de bifurcações possíveis. Essa temporalidade concerne, sob ângulos diferentes, a todos os humanos em contato com dispositivos, quaisquer que sejam os papéis que ocupem. Ela remete aos idealizadores dos dispositivos que tinham por 
alvo a organização de uma sucessão de sequências. A noção de "script" traduz bem essa intenção dos idealizadores de antecipar e de organizar condutas por meio de um agenciamento solidário de elementos (Akrich, 1987). Essa extensão temporal é igualmente importante para os que participam da realização do dispositivo. Confrontados com esse encadeamento, eles dependem uns dos outros ao longo de uma cadeia de operações. Eles têm igualmente a possibilidade de induzir, cada um em seu nível, jogos de bifurcação entre as sequências. Essa temporalidade afeta, além disso, os indivíduos que são alvo dos dispositivos, os quais se encontram expostos a essas sucessões de sequências, para uns já concebidos como conjunto de ramificações mais ou menos definido. As escalas de temporalidade para os indivíduos-alvo podem variar. Certos dispositivos se exercem durante alguns instantes sem que sua complexidade seja, contudo, reduzida. É o caso, por exemplo, de exames médicos ou de controles de fronteiras (Dodier, 1993; Linhardt, 2001). Outros podem durar longos anos, tais como os dispositivos psicoterapêuticos ou procedimentos judiciários.

Como outras abordagens, a definição proposta retoma a ideia segundo a qual um dispositivo carrega consigo finalidades. Estas são, entretanto, formuladas de tal modo que um grande número dentre elas possa encontrar o seu lugar no dispositivo. A definição não aprisiona a análise em um modelo funcional, mas abre-se para uma abordagem atributiva de finalidades. A noção de qualificação de estados de coisas acentua a finalidade idiomática de dispositivos. Ela remete ao fato de que certos dentre eles podem ser dispositivos de "provas" (épreuves) (Boltanski \& Thévenot, 1991; Barthe et alii, 2013). A noção de transformação acentua a ação linguística ou não - do dispositivo sobre o estado de coisas e sobre o fato de que essas transformações podem revelar-se centrais do ponto de vista das finalidades que Ihes são atribuídas.

Duas linhas de pesquisa podem ser trilhadas para medir os dispositivos, a sua consistência e as suas facetas. A primeira linha consiste em estudar os propósitos dos atores enquanto tais. Confrontados com situações ou questões problemáticas, os atores fazem referência a elementos que, articulados uns com os outros, aparecem progressivamente como ingredientes pertinentes de um dispositivo. Controvérsias em torno de um teste clínico tornam, por exemplo, o sociólogo atento a toda uma série de elementos que, reunidos entre si, entram na composição de um teste: categorias de identificação dos indivíduos (diagnósticos ou sociais), marcadores biológicos, técnicas estatísticas, atores econômicos, papéis, categorias ético-jurídicas etc. (Barbot, 2002; Dodier, 2003). A segunda linha de pesquisa consiste em seguir os elos endógenos dos elementos no interior do dispositivo: um texto se refere a um outro, um objeto está relacionado a outro, uma sequência chama por outra pelas 
13. Para indicações metodológicas mais precisas, relativas ao exame "em repouso" dos elementos de dispositivo mobilizados em consultas de medicina do trabalho (manuais de clínica médica, quadros de doenças, protocolos de pesquisas estatísticas) sobre os riscos dos profissionais, ver Nicolas Dodier, (1993: 47-50). ações que realiza ${ }^{13}$. Ao combinar essas duas linhas de investigação, a composição do dispositivo e o trabalho normativo de indivíduos a seu respeito revelam-se de modo interativo.

A pesquisa sobre os dispositivos associa fortemente, portanto, duas frentes de investigação que se remetem uma à outra: compreender como os atores problematizam os dispositivos, globalmente ou por fragmentos; tomar por si próprio as medidas de solidariedade estabelecidas entre elementos que, pouco a pouco, ganham a consistência de um dispositivo. Uma latitude é dada ao pesquisador, nesta perspectiva, para circunscrever o momento em que a iluminação recíproca das duas linhas de pesquisa Ihe parece atingir um limiar pertinente. $O$ fato de que, em vista de uma tal pesquisa, dispositivos encontrem-se encadeados uns com os outros não está obviamente excluído e pode ser levado em consideração.

As possibilidades de traduzir em inglês o conceito de dispositivo, tal como ele é mobilizado nos trabalhos de língua francesa, são relativamente numerosas: apparatus, device, mechanism, assemblage etc. A escolha de um desses termos reflete geralmente a vontade de o tradutor realçar, frequentemente de modo implícito, tal ou tal propriedade visada pelo conceito: assemblage acentua a heterogeneidade; device e apparatus dão visibilidade ao dispositivo sob um ângulo funcional; apparatus sublinha a dimensão da materialidade; mechanism sugere o caráter compacto e coercitivo do conjunto. Se certos trabalhos preservam a palavra francesa "dispositif" (dispositivo), eles se referem mais frequentemente ao conceito tal como foi desenvolvido na interseção da filosofia e da história por Michel Foucault, Gilles Deleuze e Giorgio Agamben (2007). Pesquisadores de língua inglesa conceituaram igualmente, de modo autônomo, os termos apparatus, assemblage, platform etc. Fazem, por vezes - mas nem sempre - referência ao conceito francês de dispositivo ou à sua tradução em inglês. Eis aqui toda uma configuração semântica que seria conveniente examinar no curso de uma investigação conceitual mais ampla.

\section{O repertório normativo em torno dos dispositivos}

Um dos interesses em examinar os dispositivos a partir do trabalho normativo dos indivíduos que se encontram em contato com eles reside no fato de que podemos isolar, sob certas condições, a base na qual esse trabalho assenta. Fala-se, assim, do "repertório normativo em torno de um dispositivo" tanto como aquilo que reagrupa o conjunto de expectativas normativas às quais os atores se referem em suas avaliações - positivas ou negativas - em torno de um dispositivo, quanto como os esquemas de julgamento que esses atores produzem em relação a essas 
expectativas. Falar sobre a existência de um repertório normativo não significa que essas expectativas sejam congruentes umas com as outras, nem que os julgamentos formem um todo coerente. Isto significa que se pode listar essas expectativas e compreender de que maneira os indivíduos elaboram julgamentos na interseção de várias delas ${ }^{14}$.

É essa estruturação do trabalho normativo pelas expectativas heterogêneas que a noção de repertório busca, de maneira geral, apreender nas ciências sociais. Uma retomada dos três principais usos dessa noção pode ajudar a compreender a característica de nossa abordagem da normatividade.

Um primeiro uso remete a uma abordagem estratégica da normatividade. O repertório é aqui observado como a paleta de recursos mobilizáveis pelos atores em um dado contexto para realizar um determinado objetivo. É o sentido, por exemplo, que Charles Tilly (1984) dá ao "repertório de ação ", entendido como o conjunto de modos de ação suscetíveis de serem utilizados por um grupo, em um dado período, para fazer valer seus interesses.

É ainda nesse sentido que Ann Swidler (1986) fala de um "repertório cultural", concebido como o conjunto de elementos que, apresentando-se aos atores sob a forma de uma "caixa de ferramentas" (toolkit), permite dar forma a uma estratégia de ação e legitimá-la, reforçá-la. Quanto a nós, nós buscamos, por meio da noção de repertório normativo, dar conta do conjunto de intenções a que os atores fazem referência quando confrontados com um dispositivo, mais até do que ao conjunto de recursos que thes permite reforçar um interesse particular.

O segundo uso da noção de repertório remete a uma abordagem fundacional da normatividade. Ao buscar reconstruir as bases de avaliação de sociedades caracterizadas pela heterogeneidade de referências normativas, Michèle Lamont e Laurent Thévenot partem da hipótese que cada princípio corresponde a um "repertório de avaliação" (Lamont, 1995; Lamont \& Thévenot, 2000) concebido como o conjunto coerente de julgamentos construídos em torno desse princípio ${ }^{15}$. A prática de avaliação ou de julgamento é então considerada como a articulação entre vários princípios e, portanto, entre vários repertórios ${ }^{16}$. Essa abordagem põe em evidência o papel crucial desempenhado por uma série de critérios de avaliação em uma sociedade; mostra de que maneira as variações entre sociedades podem ser interpretadas em termos de ponderação de critérios. Ela indica quais são os principais esquemas de julgamentos elaborados em torno desses critérios. O foco nos critérios fundadores, contudo, corre o risco de levar à superestimação da capacidade de cada qual produzir um mundo coerente de julgamentos. Por isso, escolhemos

\author{
14. Para a \\ apresentação de uma \\ abordagem destinada \\ a identificar os \\ "modelos práticos" \\ que se combinam \\ nos momentos de \\ avaliação, ver John R. \\ Bowen et alii (2014). \\ 15. É igualmente uma \\ análise fundamental \\ da normatividade \\ que é desenvolvida \\ por Luc Boltanski et \\ Laurent Thévenot \\ (2001), mesmo se \\ a noção de "mundo \\ comum" fundada \\ sobre um "princípio \\ de ordem" tende a \\ substituir, nessa obra, \\ a de "repertório". \\ 16. Ver, para um \\ emprego próximo da \\ noção de repertório, \\ Baudouin Dupret \\ (2000) acerca \\ dos diferentes \\ repertórios que \\ se articulam no \\ julgamento jurídico; \\ ou ainda Pierre \\ Lascoumes e Philippe \\ Bezes (2009) sobre \\ os repertórios a \\ partir dos quais os \\ cidadãos julgam os \\ políticos.
}


17. A expectativa normativa situa-se, portanto, entre a intenção e o ideal. Ela designa as intenções que têm por característica serem acompanhadas de uma pretensão à legitimidade, mas o alcance das intenções em questão pode ser menos geral ou menos intensamente valorizado do que um ideal. Utilizamos, em um trabalho anterior, a noção de "bem em si" para qualificar as intenções (por exemplo, a saúde em certas arenas de debates) que, pelo fato de valerem tanto, supõem-se que podem encerrar a argumentação, aos olhos de seus enunciadores (Nicolas Dodier, 2005: 7-31). A noção de expectativa normativa ampliou o olhar considerando as intenções que acompanham as pretensões à legitimidade menos abruptas do que nos casos de bens em si.

18. Essa abordagem da temporalidade adere ao método desenvolvido por Fanny Cosandey (2016) em seu estudo sobre duelos no Antigo Regime na França. A autora põe em evidência, em um primeiro momento, o que ela chama de grammaire du rang (gramática da posição), que remonta a um longo período de julgamentos de definir um repertório normativo não a partir de um princípio fundador, mas a partir do conjunto de avaliações produzidas por um aglomerado de atores em torno de um dispositivo e, portanto, do conjunto de expectativas normativas nas quais se assentam os repertórios em questão.

O terceiro uso da noção de repertório remete a uma abordagem globalizante da normatividade. Esta é distinta das noções de sistema, cultura, ou representação, que tendem a acentuar a coerência relativa das referências normativas em um dado grupo. Ela toma o repertório como a estrutura normativa que serve de base para os julgamentos produzidos em um grupo. Essa é, notadamente, a abordagem proposta por John Comaroff e Simon Roberts (1981) em seus estudos sobre a sociedade Tswana. Os autores falam do repertório normativo dos Tswana como o repertório de normas que esses últimos consideram como condutores de sua vida cotidiana (Comaroff \& Roberts, 1981: 27). Segundo eles, os Tswana têm consciência de que existe uma variedade de normas, eventualmente contraditórias, em sua sociedade (Comaroff \& Roberts, 1981: 73). Mesmo se essas normas não constituem um sistema, os autores consideram que elas podem, ainda assim, revelar a sua "estrutura semântica" (Comaroff \& Roberts, 1981: 261). Nossa noção de repertório normativo se aproxima do uso que fazem John Comaroff e Simon Roberts, já que buscamos, como eles, dar conta da estrutura da base de avaliações de um conjunto de atores, na intersecção de diferentes referências normativas. No entanto, nossa noção se distingue da de Comaroff e Roberts em dois pontos. Eles focam o conjunto do trabalho normativo em uma sociedade, enquanto nós nos interessamos por cada repertório normativo em seu posicionamento vis-à-vis ao dispositivo. A noção de Comaroff e Roberts de norma é, além disso, mais restritiva do que a nossa noção de expectativa. A noção deles remete às situações caracterizadas pela existência de uma regra. Nós consideramos, através da noção de expectativa, o conjunto de situações nas quais os indivíduos exprimem uma perspectiva que thes parece suficientemente admissível para sustentar um julgamento legítimo. Ficamos abertos à variedade de intermediários pelos quais a legitimidade dessa expectativa é expressa ${ }^{17}$ : valores, regras, normas princípios, finalidades etc.

Falar de um repertório normativo em torno de um dispositivo leva a uma abordagem particular da temporalidade. Trata-se, antes de tudo, de atualizar, por um dado período, a estrutura normativa que se encontra na origem do conjunto de avaliações em torno de um dispositivo. Sob esta base de dados estabelecida de modo Icaro, trata-se, em seguida, de estar atento às variações temporais. Esta estratégia permite conjugar, sem confundi-las, uma abordagem estrutural do trabalho normativo e uma consideração acerca das dinâmicas temporais a ele relacionadas ${ }^{18}$. 
Ao organizar dessa forma o estudo de repertórios normativos, faz-se necessário separar, de um lado, os dispositivos e, de outro, o trabalho normativo dos atores, a fim de melhor pensar sua interação. Essa exigência não foi suficientemente considerada até aqui. Trata-se de uma limitação encontrada, notadamente no trabalho de Foucault, já que o autor aborda o dispositivo como um conjunto muito abrangente de entidades, próprio a uma determinada época, no interior do qual os indivíduos ou os grupos elaboram práticas ou problematizam situações do próprio dispositivo. Em Foucault, o dispositivo é o quadro no interior do qual o trabalho normativo surge e é organizado. A noção de "dispositivo da sexualidade" permite-lhe, assim, listar o conjunto de elementos, discursivos ou não, pelos quais os indivíduos, em um momento histórico, identificam situações, elaboram práticas, constroem estratégias, falam ou escrevem em torno de uma certa esfera de problemas delimitados e tornados pertinentes pelo dispositivo. Com nossa definição menos abrangente de dispositivos, consideramos, ao contrário, que os julgamentos produzidos no contato com um dispositivo revelam uma base normativa que não está presente nele, mesmo se pode ser influenciada por ele. Foucault certamente incorpora uma indeterminação das práticas, o que faz com que o funcionamento dos dispositivos deixe aparecer, segundo ele, certos imprevistos que são reinvestidos pelos indivíduos. Os dispositivos são, assim, "lugares de preenchimento"19. Mas as bases normativas desse preenchimento continuam mal elucidadas, pois são devolvidas às configurações emergentes pensadas em sua contingência. Mais do que analisar a dinâmica engendrada pelo encontro entre um dispositivo e seus imprevistos, buscamos compreender as interações entre dispositivos e os repertórios normativos que se elaboram acerca dos próprios dispositivos.

Esse excesso de vinculação entre as bases normativas de julgamento e dispositivos é igualmente um limite das abordagens de uma sociologia pragmática dos "regimes de engajamento". Essa abordagem tende a situar cada dispositivo em uma ordem maior. Segundo os autores, pode tratar-se DE um "regime de engajamento", de um "mundo", de uma forma de coordenação. Uma forma de harmonia é, então, supostamente atingida assim que os indivíduos se encontram imersos em um estado compativel com essa ordem. Espera-se que as tensões apareçam a partir do momento em que as entidades relacionadas às diversas ordens são colocadas em relação umas com as outras. Essas tensões podem ser superadas por compromissos, graças, notadamente, aos dispositivos, os quais têm por particularidade combinar de maneira judiciosa os elementos relacionados a diferentes ordens. Não partimos deste postulado de correspondência entre dispositivos e ordens normativas. É por essa razão, entre outras, que concebemos um método que permite identificar a base normativa das avaliações que se constroem em torno dos dispositivos. cortesãos sobre as hierarquias estabelecidas no quadro do dispositivo cerimonial na corte real francesa. É, em um segundo momento e sobre essa base de algum modo estatístico, que ela mostra os jogos de relações entre atores e suas transformações no seio dessa gramática. A noção de gramática remete a uma abordagem mais fundacional que a de repertório normativo, mas o foco sobre os dois tempos de análise é formulado de maneira análoga.

19. Segundo expressão de Laura Silva-Castañeda (2012: 102) 


\section{Os dispositivos de reparação}

Para precisar como essa abordagem dos repertórios normativos em torno dos dispositivos foi, ao mesmo tempo, elaborada e empregada, propomos voltar a diferentes trabalhos nos quais a mesma ganhou corpo. Nesses trabalhos, tratamos de uma forma geral dos dispositivos de reparação: processos, fundos de indenização, seguros etc. A fim de compreender o que "reparar" quer dizer, exploramos para cada um desses dispositivos as redes de finalidades e exigências que os diferentes atores por elas confrontados Ihes atribuem. A primeira destas pesquisas está centrada em uma categoria de atores (os profissionais do direito) e sobre um dispositivo (o processo penal). Em um contexto caracterizado pelo crescimento do lugar das vítimas nos procedimentos penais, estudamos, em duas arenas distintas, como os profissionais do direito problematizaram essa questão: o debate doutrinário e a audiência em um processo penal. A segunda pesquisa desloca o olhar para outro dispositivo de reparação (um fundo de indenização) e para outra categoria de atores (as "vítimas" que do fundo são beneficiárias). A última pesquisa, mais prospectiva, explora em que a abordagem dos dispositivos e dos repertórios normativos pode contribuir para o estudo das transformações das condições de reparação de danos relacionados à atividade médica que ocorreram durante um longo período. A variedade de dispositivos, de arenas e de ordens de temporalidade consideradas nestas pesquisas deveria permitir uma melhor delimitação do campo de aplicação da abordagem proposta.

\section{O trabalho doutrinal em torno do processo penal}

Nós nos interessamos pelo trabalho doutrinal que os juristas realizam há trinta anos na França e nos Estados Unidos acerca de uma questão problemática: o lugar das vítimas no processo penal (Barbot \& Dodier, 2014a). Trata-se de estudar o trabalho normativo de uma categoria de atores acerca de um dispositivo.

Esta pesquisa permitiu precisar o que podemos reter sob o termo genérico de expectativas (ou, mais precisamente, de expectativas normativas) e sobre seu papel no quadro de um repertório normativo. Ela mostra que o conjunto de tomadas de posição dos juristas na França e nos Estados Unidos sobre o lugar das vítimas no processo penal se organiza em torno de duas grandes séries de expectativas.

A primeira corresponde às finalidades que os juristas atribuem ao processo. Encontra-se aqui uma dimensão do trabalho normativo cuja importância indicamos acima. Dá-se conta igualmente do interesse que há, de uma perspectiva metodológica, em não restringir o estudo de um dispositivo a uma visão preconcebida acerca das finalidades que ele deve cumprir. Com efeito, a natureza das finalidades de um dis- 
positivo tal como o processo penal pode se revelar altamente problemática e fonte de controvérsias, do ponto de vista dos especialistas do direito.

É certo que, desde o século XVIII, o trabalho doutrinal sobre o processo foi organizado em torno de uma base de finalidades clássicas: a retribuição do crime, a prevenção do crime, a reabilitação do condenado e a neutralização do criminoso ${ }^{20}$. No entanto, em um contexto marcado há 30 anos pela ampliação do lugar das vítimas, os juristas se interrogam de forma inédita sobre a pertinência de novas finalidades que poderiam se adicionar às precedentes: a indenização das vítimas, a finalidade terapêutica ou reconstrutiva do processo, o empoderamento das vítimas, ou ainda a contribuição do processo para a ação política.

O estudo do trabalho doutrinal em torno do processo penal mostra a importância, para além dessas finalidades, de uma segunda série de expectativas. Esta concerne aos princípios a serem respeitados quando da implementação do dispositivo. Se a atenção dada às finalidades conduz os atores a julgarem o dispositivo tendo em vista aquilo que ele provoca nos indivíduos concernidos, a atenção dada aos princípios remete às exigências que convém seguir para o seu bom encaminhamento. As duas categorias de expectativas podem, por sua vez, se juntar. Todavia, distingui-las permite evidenciar os diferentes horizontes de expectativas. Enquanto as discussões relativas às finalidades integram um olhar sobre os efeitos do dispositivo, aquelas relativas aos princípios remetem às diferentes etapas de sua realização. Três princípios aparecem como centrais no trabalho doutrinal em torno do lugar das vítimas no processo penal: a objetividade de decisões; a equidade do processo; e a dosagem justa dos sofrimentos induzidos pelo processo em seus protagonistas (acareação e partes civis, particularmente).

A análise do repertório normativo dos juristas tal como ela foi conduzida nesse estudo é um método inédito para compreender melhor como se estrutura o espaço dos atores em torno de um dispositivo. Em seu trabalho doutrinal, percebe-se, por exemplo, que os juristas divergem profundamente quanto à natureza das finalidades que se deve atribuir hoje ao processo penal. Alguns militam pela ampliação das finalidades do processo, enquanto outros lutam contra isto que consideram como desvios do dispositivo. Todos os juristas são unânimes no que tange ao reconhecimento da legitimidade de três princípios a serem respeitados no desenvolvimento de um processo. No entanto, divergem sobre a maneira de satisfazê-los. Assim, as concepções diferentes de objetividade no processo penal se afrontam na arena doutrinal ${ }^{21}$, e os juristas consideram de forma diferente o que poderia ser um justo equilíbrio dos sofrimentos infligidos aos atores presentes. Um dos maiores desafios para a identificação de um repertório normativo é evidenciar tudo ao

20. Para lembrar as finalidades habitualmente atribuídas no processo penal pelos especialistas do direito, ver Henderson (1985). Acerca dos debates sobre o surgimento do código penal na França e os grandes tipos de pena em torno dos quais se estruturam os debates, ver Lascoumes et alii (1989). Para um retorno sobre as finalidades geralmente atribuídas ao processo penal ou à pena - pelos filósofos, ver Gros (2001) e Guillarme (2003).

21. Esse confronto entre concepções opostas de objetividade está no centro das lutas que rodeiam os numerosos dispositivos. Mas essas lutas em torno da objetividade tomam as formas específicas segundo os dispositivos considerados. Para uma comparação com o processo penal, ver as lutas na medicina em torno de ensaios clínicos em Dodier \& Barbot (2008). 
22. No que tange às políticas penais, ver Latté (2008) e Enguéléguélé (1989).

mesmo tempo, isto é, o que há de comum em um espaço de atores, bem como o que os diferencia e os opõe em seus respectivos posicionamentos.

Com essa abordagem, exploramos as diferentes maneiras pelas quais os especialistas do direito consideram, na intersecção dessas finalidades e princípios, o lugar das vítimas no processo penal.

Identificamos, por exemplo, duas maneiras doutrinais de ser "pró-vítimas", elas mesmas em conexão com opções diferentes em matéria de políticas penais ${ }^{22}$. De um lado, os juristas queriam ampliar o espaço conferido às vítimas e aos seus representantes no sistema penal, militando por um aumento da repressão. Esse movimento foi iniciado nos Estados Unidos, nos anos 1970-1980, através dos elos estabelecidos entre os círculos conservadores de luta contra a criminalidade e os grupos de defesa das vítimas em busca de apoio institucional. Na França, desde 1975, as políticas penais são igualmente orientadas na direção de um aumento da repressão, apoiada por um interesse renovado pelas vítimas. De outro lado, os juristas construíram uma maneira mais liberal de serem pró-vítimas. Nos Estados Unidos como na França, eles fazem parte dos atores que buscaram melhorar a condição das vítimas de infrações penais, ainda que sem aumentar a repressão. Esses atores começaram a favorecer os dispositivos fora do processo: melhoria das condições de indenização, apoio psicológico, criação de instâncias de mediação.

Na França, nos anos 1980, sob a supervisão do ministro da Justiça Robert Badinter, eles buscaram uma alternativa à "Lei Segurança e Liberdade" e instauraram uma nova política de ajuda às vítimas, mediante a criação de uma rede associativa dirigida pelo Estado: o Institut Aide aux Victimes et Médiation (Instituto Nacional de Ajuda às Vítimas e de Mediação). No início do século XXI, os juristas que pertenciam ao polo liberal contribuíram para aumentar a presença das vítimas no âmbito do processo penal, notadamente através das disposições da "Lei Guigou", referência ao então ministro socialista da Justiça, sobre a presunção de inocência e os direitos das vítimas. Mais amplamente, pode-se compreender por essa via como os espaços de atores ancorados em arenas especializadas se articulam com o campo político.

\section{O trabalho dos advogados na audiência penal}

No caso precedente, abordamos o trabalho normativo dos atores sobre um dispositivo. É com um método similar que examinamos o trabalho realizado pelos atores no interior deste dispositivo. Por meio dos circuitos de reflexividade, os atores que se encontram engajados em um dispositivo frequentemente procuram, no curso de 
sua implementação, influenciar, ao mesmo tempo, a conduta e o resultado do próprio dispositivo. Estudamos justamente sob este ângulo as alegações de advogados durante um processo penal (Barbot \& Dodier, 2014b). Como na pesquisa precedente, nós nos interessamos particularmente pela regulação do lugar das vítimas no processo, mas, desta vez, examinando como os advogados voltam-se, durante a audiência, para o modo como os diferentes atores do processo (os magistrados da procuradoria, os juízes, os demais advogados, as partes civis) se comportam ou deveriam se comportar em relação às vítimas.

Esse estudo se apoia em uma etnografia sobre o processo de primeira instância relativo a um caso (affaire) de saúde pública. Na audiência, a presença das famílias das vítimas foi particularmente importante e suscitou um intenso trabalho normativo intenso por parte do conjunto de atores presentes. Trata-se do processo penal subsequente às contaminações iatrogênicas ${ }^{23}$, nos anos 1980, de tratamentos destinados a crianças com problemas de crescimento ${ }^{24}$. A tramitação desse processo ocorreu em 2008, no Palácio da Justiça de Paris, passados mais de 17 anos do início da instrução. Nesse quadro, mostramos que o conjunto das intervenções dos advogados para construir um relatório apropriado às vítimas se referia, ainda aqui, a um conjunto preciso de expectativas normativas. Quatro dentre elas foram centrais e compartilhadas pelos advogados, independentemente de seu posicionamento no processo (do lado da defesa ou do lado das partes civis): a humanidade das condutas em face dos testemunhos de sofrimento, a objetividade da decisão penal, o ajuste dos sofrimentos induzidos pelo processo entre os acusados e as vítimas, assim como o distanciamento de uma finalidade terapêutica do processo. Mesmo se os advogados dos dois campos estavam do mesmo lado no que diz respeito a essas expectativas, eles se opuseram no que concerne à maneira de satisfazê-las e de articulá-las umas com as outras. Segundo as estratégias judiciárias ajustadas a cada um de seus campos, os advogados descreveram, de forma contrastante, a maneira como os juízes deviam integrar suas próprias reações aos sofrimentos das vítimas na elaboração de uma decisão penal.

Considerados em conjunto, esses dois estudos sobre o processo penal mostram a importância dos efeitos da arena sobre os repertórios normativos. Em cada caso, os atores, profissionais do direito, tratam da mesma questão problemática: o lugar das vítimas no processo penal. Porém, eles o abordam em duas arenas distintas: a arena doutrinal no primeiro caso, a audiência penal (e mais particularmente o momento de alegações) no segundo ${ }^{25}$. Se os dois repertórios possuem semelhanças importantes, eles apresentam igualmente diferenças notáveis. Assim, a exigência de compaixão para com as famílias das vítimas presentes na audiência esteve no centro do trabalho normativo no curso do processo observado, notadamente atra-

\author{
23. Termo \\ farmacológico para \\ designar uma doença \\ criada pelo efeito \\ colateral de um \\ medicamento. \\ 24. Mais de uma \\ centena de crianças \\ morreu por conta \\ dos tratamentos \\ de contaminação \\ pelo príon (agente \\ responsável \\ pela doença de \\ Creutzfeldt-Jakob). \\ 25. Podemos definir \\ uma "arena" como \\ um dispositivo \\ que organiza \\ uma forma de \\ reflexividade sobre \\ outro dispositivo. \\ Uma arena pode \\ ser interna ao \\ dispositivo, quando \\ esta prevê e organiza \\ as condições nas \\ quais as ondas de \\ reflexividade podem \\ ser associadas a sua \\ própria execução. É o \\ caso da sequência de \\ alegações no interior \\ de um processo.
}


vés da questão de sua articulação com a exigência de objetividade. Essa exigência foi sustentada por todos os advogados em suas alegações. Em contrapartida, ela foi pouco invocada pelos juristas que participaram do trabalho doutrinal do processo; alguns chegaram a defender um distanciamento radical das emoções. Inversamente, a finalidade "terapêutica" do processo, regularmente destacada por uma parte dos juristas na arena doutrinária, jamais foi evocada como sendo legítima pelos advogados na audiência. Diversos parâmetros se transformam quando mudamos de arena: os atores envolvidos, os modos de acesso às realidades pertinentes, os alvos do trabalho normativo, assim como os formatos que coagem e o tornam possível. Essa primeira perspectiva do trabalho doutrinal e do trabalho na audiência permite dar conta do transcurso do repertório normativo de uma mesma categoria de atores - aqui, os profissionais do direito -, de uma arena à outra.

\section{As vítimas em face de um fundo de indenização}

Abordamos igualmente a maneira como os atores se posicionam vis-à-vis a um dispositivo do qual são alvos. Este estudo toma por exemplo o fundo público de indenização destinado às pessoas atingidas pelo drama sanitário das contaminações pelo hormônio de crescimento. Estudamos a maneira pela qual os beneficiários desses fundos reagiram à sua criação e à sua execução. Com base em 40 entrevistas, evidenciamos o repertório normativo de pessoas que, como compensação do prejuízo que sofreram, propõem, enquanto vítimas, uma indenização financeira no quadro desse dispositivo (Barbot \& Dodier, 2015a; 2015b). Através dos julgamentos que elas apresentaram sobre os fundos, destacamos o caráter central de três grandes expectativas normativas. A primeira é uma expectativa de socorro diante dos gastos causados pelo dano, em decorrência do aparecimento de doença neurodegenerativa transmitida pelos tratamentos. Uma parte das avaliações relativas ao dispositivo aborda, com efeito, sua capacidade de trazer, com urgência, um apoio financeiro às famílias confrontadas com os gastos ocasionados pelo aparecimento da doença. Contudo, as pessoas não se posicionaram da mesma maneira acerca dessa expectativa. As diferenças estão estreitamente relacionadas a seus estatutos socioeconômicos; alguns se referem ao estado de organização da assistência social e terapêutica no momento em que a doença apareceu.

A segunda expectativa é uma expectativa de justiça, entendida como a manifestação das responsabilidades morais no desenvolvimento do drama e, caso necessário, como condenação e punição dos culpados. Paralelamente às apreciações em termos de socorro, as pessoas também consideraram até que ponto o fundo podia 
contribuir para a manifestação da verdade moral ou, ao contrário, se opor a ela. Essa avaliação do fundo de indenização à luz de uma expectativa de justiça assumiu, no caso desse drama, uma tonalidade particular. Com efeito, um procedimento judiciário já tinha sido aberto no momento da criação do fundo pelo governo, e foram pronunciadas as primeiras acusações contra personalidades dos meios médico e sanitários ${ }^{26}$. Para justificar a implementação de um fundo (propondo uma indenização sem que fosse necessário provar a existência de um erro na fabricação dos medicamentos do tratamento), o governo tinha invocado a expressão da "solidariedade nacional" para com as vítimas e seus familiares. Nesse contexto, muitas famílias suspeitaram que o governo queria desencorajá-los do procedimento judiciário. O exame do trabalho normativo permite mostrar como a tensão moral suscitada por essa expectativa de justiça foi gerada pelas pessoas que, no entanto, aceitaram ser indenizadas pelo fundo.

Enfim, as famílias das vítimas se referiram a uma terceira expectativa: a compensação ajustada. Como no caso da expectativa de justiça, analisamos todo o trabalho que as famílias tiveram de realizar para formular o sentido que poderia ter essa indenização financeira como contrapartida pelo dano. As famílias que aceitaram o fundo quiseram superar o problema moral produzido pelos julgamentos de incomensurabilidade entre as somas recebidas e a natureza das violações sofridas (neste caso, aqueles diretamente relacionados com doença e com a perda de um filho $)^{27}$. De uma maneira geral, para além das finalidades atribuídas ao fundo por seus criadores, a pesquisa mostra o leque de expectativas acerca do qual aqueles que são os beneficiários construíram sua própria avaliação do dispositivo e geriram as tensões engendradas por este último.

O estudo do trabalho normativo conduz, assim, a que se preste atenção nas situações em que os indivíduos são capazes de avaliar o dispositivo a que são confrontados ou as condutas dos outros indivíduos no quadro desse dispositivo. Parte-se, portanto, de um certo nível de actância (agency) dos indivíduos em face dos dispositivos. Todavia, não se trata simplesmente de revelar essa capacidade ou de mensurar sua amplitude. A abordagem visa objetivar a base normativa a partir da qual os indivíduos constroem o caráter inteligível ou legítimo de seu posicionamento vis-à-vis a um dispositivo. Ademais, o estudo do repertório das vítimas do drama do hormônio de crescimento em torno do fundo de indenização mostra o interesse que haveria - nesse caso como em outros - em examinar com o mesmo método o repertório normativo de vítimas em torno de cada um dos dispositivos que podem ser mobilizados logo após uma catástrofe: processo (penal e civil), imprensa, meios associativos e, notadamente, apoios psicológicos ${ }^{28}$. Trata-se de
26. A primeira queixa ao penal é apresentada em 1991, as primeiras acusações são pronunciadas em julho de 1993 e o fundo de indenização é criado em outubro de 1993.

27. Sobre essas formas de incomensurabilidade, ver Viviana A. Zelizer (1979; 1985).

28. Para uma identificação convergente da maneira como as vítimas de catástrofe se posicionam em relação aos dispositivos, ver Revet \&Langumier (2013), que se centram sobre os dispositivos de concertação e os dispositivos memoriais. 
comparar a natureza das expectativas e dos esquemas de julgamento ativados pela confrontação com cada dispositivo, e em seguida de compreender sua articulação ao longo do itinerário das pessoas afetadas.

O estudo do posicionamento das pessoas vis-à-vis aos dispositivos não pretende substituir a análise de seu posicionamento vis-à-vis a outras entidades sociais: os "coletivos", as "instituições", as "redes" de relações, por exemplo. O desafio é dar conta do lugar que tais dispositivos ocupam e do trabalho normativo que eles suscitam nos atores. Nós defendemos o caráter central que esse posicionamento pode assumir nas biografias individuais ou coletivas.

\section{Para uma utilização do método em períodos de longa duração}

Por fim, exploramos o interesse dessa abordagem no estudo das transformações de modalidades de reparação de prejuízos relacionados à atividade médica, do início do século XIX aos anos 2000, na França (Barbot, 2016). Nessa perspectiva, duas linhas de análise se encontram bem articuladas: aquela das transformações de dispositivos sobre um período longo de tempo e aquela do posicionamento dos diferentes atores em torno desses dispositivos.

A abordagem consiste em identificar diversos "momentos de concentração" do trabalho normativo dos atores e a investigá-los em diferentes arenas. Durante o século XIX, um primeiro momento pode ser percebido em torno da questão da inimputabilidade médica. Reivindicada pelos médicos diante dos tribunais, a inimputabilidade havia com efeito suscitado numerosos debates nas arenas judiciárias, profissionais e midiáticas, por ocasião de três casos: os casos Hélie (1825), Laporte (1897) e Thouret-Noroy (1932). Diversas categorias de atores (médicos, juristas, personalidade políticas etc.) foram levadas a assumir uma posição. 0 trabalho normativo deles foi principalmente centrado nas modalidades de intervenção de dispositivos judiciários no domínio médico. Diferentes esquemas de julgamento se opuseram entre os defensores de uma inimputabilidade médica "absoluta" e os que desejavam colocar um fim a ela, ou rediscutir seus contornos. Outro momento de concentração do trabalho normativo concerne, entre os anos 1960 e 2000, à elaboração de novos regimes de indenização das vítimas de danos relacionados à atividade médica. Os debates intensos acompanham toda uma série de proposições ou de inovações: o projeto de reforma do professor de direito André Tunc, sugerindo, em 1966, passar de um regime de indenização das vítimas de erros médicos baseado no recurso aos tribunais (e a prova de um erro cometido 
durante a prática dos cuidados) a uma indenização custeada por um fundo de garantia profissional (que cobre o risco vinculado a esse setor de atividade); a criação de regimes de indenização específicos para as vítimas de danos relacionados às vacinas (1961), às transfusões (1964), ou às experimentações médicas (1988); o desenvolvimento de fundos públicos de indenização relativos aos dramas sanitários dos anos 1990 (notadamente as contaminações iatrogênicas relacionadas aos produtos sanguíneos e aos hormônios de crescimento); ou, ainda, a criação, pela lei de 4 de março de 2002, de um dispositivo de regulamentação amigável para as vítimas de prejuízos da atividade médica e de um novo direito à indenização das vítimas de acidentes não culposos ${ }^{29}$.

Com a identificação e análise de cada um desses momentos em que o trabalho normativo se concentra, importa seguir as transformações dos repertórios normativos dos atores em longos períodos de tempo. Os primeiros resultados dessa pesquisa mostram que, no decorrer do século XIX, os debates eram organizados em torno de três dispositivos que se impõem progressivamente na reparação dos erros médicos: os processos, os modos de regulação profissional e os seguros de responsabilidade civil dos médicos. No que concerne aos dispositivos judiciários, podemos constatar que duas expectativas - presentes em nossos trabalhos anteriores - já estruturam o repertório normativo dos principais atores estudados: a dose ajustada entre sofrimento infligido às pessoas implicadas nos procedimentos e a objetividade dos julgamentos. É de se observar que a primeira expectativa incide apenas sobre as violências produzidas contra os médicos denunciados. No início do século XIX, estes ataques geram uma perda da clientela decorrente das fofocas inevitáveis que acompanham os procedimentos, ao peso intransponível, no plano individual, dos custos que os médicos devem arrecadar para a sua defesa e, em caso de condenação, para indenizar os pacientes ou seus familiares. No curso desses debates, uma parte dos juristas e dos médicos rejeitam toda legitimidade do processo em matéria médica, pois consideram que essas violências contra os médicos devem ser evitadas, seja enquanto tal, seja em razão de seus impactos negativos sobre os progressos da medicina ou sobre os socorros prestados aos doentes. Assim, desde o início do século XIX, a figura da "medicina defensiva" faz sua aparição nos debates dos quais ela nunca mais saiu, o que já faz dois séculos ${ }^{30}$. Trata-se então da "medicina de braços cruzados", o médico praticando o abstencionismo, ou recusando deslocar-se diante de uma situação considerada difícil e arriscada no plano judiciário. No sentido oposto, os atores aceitam essas violências - ou ao menos parte delas - apoiando-se sobre outras finalidades para avaliar a intrusão dos dispositivos judiciários na atividade médica. Eles colocam, em primeiro lugar, a necessidade de manter a "ordem pública", rejeitando todo estatuto de exceção em favor dos médicos e tratando de forma igual todas as profissões que compõem a
29. Esse dispositivo foi objeto de diferentes investigações específicas, ver Barbot et alii (2014; 2015).

30. Sobre os empregos dessa figura da medicina defensiva, ver Barbot \& Fillion (2006). 
sociedade. No que tange à segunda expectativa estruturante, pode-se igualmente mostrar como o espaço dos atores se polariza entre as concepções diferentes de objetividade, tanto judiciária quanto médica.

Na segunda metade do século XX, a efervescência do trabalho dos atores em torno dos dispositivos de reparação dos erros médicos remete a duas dinâmicas maiores no plano dos repertórios normativos. Se as expectativas já estruturantes no século XIX permanecem no centro do trabalho normativo em torno dos dispositivos judiciários, as maneiras de se referir a elas evoluem. Além disso, em face da diversificação dos dispositivos de reparação e dos atores levados a falar sobre estes últimos, novas expectativas emergem e impactam profundamente os repertórios presentes. Por exemplo, se a dose de sofrimentos infligida aos médicos permanece no centro do trabalho normativo, novas figuras da "medicina defensiva" aparecem: notadamente aquela da "medicina dispendiosa", destacada de início pelos políticos que buscam limitar as prescrições intempestivas (onerosas para a coletividade) por meio das quais os médicos tentaram evitar os processos. A partir de então, a dose de sofrimentos judiciários concerne igualmente às vítimas, ligadas à emergência de novos coletivos que lhes são dedicados. As discussões em torno da construção da objetividade de decisões judiciárias encontram-se, portanto, profundamente influenciadas pelo lugar decisivo atribuído à articulação entre compaixão, acerca das vítimas e à objetividade da decisão judicial. As expectativas, de natureza inédita, emergem e são trabalhadas em relação aos novos dispositivos de indenização: a referência à solidariedade nacional para com as vítimas de erros médicos, ou ainda a pesquisa de um tratamento igualitário entre as diferentes categorias de vítimas na medicina e, mais geralmente, em toda a sociedade.

É assim que, frequentemente na intersecção de diversos dispositivos, os atores pensam a reparação de erros médicos. A transformação das condições de reparação não procede da substituição de um dispositivo por outro, mas da reorganização global do trabalho normativo quando novos dispositivos e novas expectativas entram em cena. O interesse em distinguir esses dois níveis de análise (o dos dispositivos e aquele das bases normativas sobre as quais eles são trabalhados) aparece então claramente. Trata-se de uma diferença importante com relação à abordagem, mais foucaultiana, que François Ewald (1986) elaborou para pensar a transformação das condições da reparação no setor dos acidentes de trabalho e das doenças profissionais. Para Ewald, a transformação que se efetua neste setor, no fim do século XIX, pertence a um mesmo bloco de dispositivos (as categorias, as leis e as práticas): tudo se passa como se a sociedade mudasse globalmente de um paradigma de responsabilidade para outro. É importante, para melhor dar-se conta dos efeitos sobre a dinâmica da história, dissociar dispositivos e repertórios normativos. Com base 
nessas transformações conjuntas, pode-se então esclarecer sob nova luz a história das instituições - judiciárias e securitárias.

O método que propomos é destinado a pensar o lugar dos dispositivos no exercício da normatividade. Este método pode desenvolver-se segundo diversas ordens de temporalidade. Ele pode abordar a implantação de cada dispositivo considerado como o conjunto de recursos que, agenciados uns aos outros, preparam, sem determiná-lo, um encadeamento de sequências. É, então, o trabalho normativo sobre e no dispositivo, durante o tempo de seu exercício, que está no centro da análise. Pode-se abordar igualmente com esse método o tempo biográfico de cada indivíduo. A trajetória de um indivíduo é então concebida como confrontação simultânea e sucessiva de um conjunto de dispositivos marcantes. Ao examinar o trabalho normativo dos indivíduos no contato com os dispositivos que os têm como alvo, discerne-se, ao mesmo tempo, os efeitos do dispositivo sobre esses indivíduos e a maneira como, por sua vez, os próprios indivíduos os realizam e até mesmo, por vezes, os modificam. Pode-se por fim tratar, sob o ângulo de uma temporalidade histórica, do jogo cruzado dos dispositivos e dos repertórios normativos a eles relacionados.

Em nossos trabalhos, consideramos até aqui cada ordem de temporalidade de maneira separada. Pode-se, no prolongamento desses trabalhos, observar formas de articulação entre essas diferentes ordens; pode-se, por exemplo, buscar uma compreensão mais acurada do efeito das trajetórias dos indivíduos, elas próprias concebidas como confrontações com os dispositivos, na maneira como eles abordam os novos dispositivos a que fazem face. Já a compreensão das transformações de longo termo pode esclarecer a maneira como as experiências individuais de um dispositivo se integram em uma história. É assim que a pesquisa conduzida sobre a história da reparação de erros médicos mostra como o fundo de indenização proposto às vítimas do hormônio de crescimento contaminado inscreve-se em uma geração específica de dispositivos imaginados, a partir dos anos 1990, na gestão de catástrofes sanitárias com danos reputados particularmente graves, capazes inclusive de colocar questões complexas de responsabilidade.

Quaisquer que sejam as ordens de temporalidade investidas pelo pesquisador, a natureza e o tamanho das observações necessárias para objetivar a estrutura do repertório normativo em torno de um dispositivo variam em função do grau de complexidade dessa estrutura. Esta não emerge senão progressivamente, no curso da investigação. O critério de saturação dos dados, tal qual Barney Glaser e Anselm Strauss (1967) o formularam, aplica-se muito bem para a tradução dessa exigência de uma repetição de esquemas de julgamento como sinal de que o repertório normativo está prestes a ser objetivado. É globalmente no reencontro das caracterís- 
ticas próprias a cada dispositivo e a cada repertório que as escalas de investigação podem ser decididas. O método que propomos não é a priori, nem micro ou macro, mas oferece as pistas para encontrar as escalas de observação adequadas para cada caso.

À semelhança de outros pesquisadores que conceituaram a noção de dispositivo, defendemos neste artigo a especificidade ontológica dos seres sociais assim designados e o interesse que se pode ter em desenvolver um método específico de investigação sobre eles. Porém, os outros seres sociais não são esquecidos. Com efeito, eles estão presentes no trabalho normativo em torno dos dispositivos. De maneira geral, o fato de os indivíduos terem de se posicionar vis-à-vis aos dispositivos ativa ou transforma sua relação com os demais seres sociais. Essa constatação pode se aplicar a cada um dos exemplos apresentados neste texto. Juristas reavaliam as missões que atribuem a uma entidade, tal como o Estado, quando trabalham sobre as finalidades do processo penal em relação ao lugar das vítimas. Os advogados enunciam o que significa, os seus olhos, ser "humano" quando especificam em que e até que ponto a compaixão pode ser introduzida no tribunal. Cada vítima explicita sua relação com os diferentes coletivos de vítimas engajadas no caso do hormônio contaminado quando ela explica a posição que assumiu vis-à-vis ao fundo público de indenização. Os juristas, médicos, políticos e ativistas definem o que é para eles "a relação médico-doente" quando buscam estabelecer os dispositivos mais capazes de reparar os danos vinculados à atividade médica. É, portanto, a identificação dessas reorganizações possíveis da relação como o conjunto dos seres sociais, por meio da consideração da força dos dispositivos, que o método proposto deseja igualmente contribuir.

Abstract: Social sciences have much to gain by paying particular attention to the place that dispositifs occupy in social life. The utility of such a perspective is evident from an examination of the research that has made use of this notion since the end of the 1970s. Yet in addition to the wide variety of definitions and objectives relating to the concept of dispositif, a reading of these works also reveals some of the difficulties that have been encountered along the way. An effort to clarify and renew the discussion on both conceptual and methodological levels is thus worthwhile, and this article is a contribution to this end. The first section sets out a conceptual inquiry into the notion of dispositif. The second puts forward a series of propositions designed to develop a "processual" approach to dispositifs. Finally, we return to several studies that we have conducted from this perspective relating to the dispositifs of redress, looking at the doctrinal work of jurists involved in a criminal trial, the practices of lawyers in the courtroom, the reactions of victims of a disaster to a compensation fund, and the historical transformations of dispositifs of redress for medical accidents since the beginning of the nineteenth century. This enables us to specify the approach we propose and to suggest new avenues for the future.

Keywords: sociologycal theory, french pragmatism, dispositifs. 


\section{Referências}

AGAMBEN, Giorgio. Qu'est-ce qu'un dispositif? Paris: Payot et Rivages, 2007 [2006].

AKRICH, Madeleine. Comment décrire les objets techniques? Techniques et Culture, v. 9, p. 49-64, 1987.

AKRICH, Madeleine; CALLON, Michel; LATOUR, Bruno. À quoi tient le succès des innovations? 1. L'art de l'intéressement. Annales des mines. Gérer et Comprendre, n. 11, p. 4-17, 1988.

BARBOT, Janine. La médecine en procès. Contribution sociologique à l'histoire de la réparation des accidents médicaux. Mémoire d’Hdr. Grenoble: Université Pierre Mendès-France, 2016.

- Les malades en mouvements. La médecine et la science à l'épreuve du Sida. Paris: Balland, 2002.

BARBOT, Janine; DODIER, Nicolas. "Victims" normative repertoire of financial compensation: the tainted hGH case. Human Studies, v. 38, n. 1, p. 81-96, 2015 a.

_. Face à l'extension des indemnisations non judiciaires. Le cas des victimes d'un drame de santé publique. Droit et Société, v. 89, n. 1, p. 89-103, 2015b.

- Repenser la place des victimes au procès pénal. Le répertoire normatif des juristes en France et aux États-Unis. Revue Française de Science Politique, v. 64, n. 3, p. 407-434, 2014a.

Que faire de la compassion au travail ? La réflexivité stratégique des avocats à l'audience. Sociologie du Travail, v. 56, n. 3, p. 365-385, 2014b.

BARBOT, Janine; WINANCE, Myriam; PARIZOT, Isabelle. Imputer, reprocher, demander réparation. Une sociologie de la plainte en matière médicale. Sciences Sociales et Santé, v. 33, n. 2, p. 77-105, 2015.

BARBOT, Janine; PARIZOT, Isabelle; WINANCE, Myriam. "No-fault" compensation for victims of medical injuries: ten years of implementing the French Model. Health Policy, v. 114, n.2-3, p. 236-245, 2014.

BARBOT, Janine; FILLION, Emmanuelle. La "médecine défensive": critique d'un concept à succès. Sciences Sociales et Santé, v. 24, n. 2, p. 5-33, 2006.

BESSY, Christian; CHATEAURAYNAUD, Francis. Experts et faussaires. Pour une sociologie de la perception. Paris: Métailié, 1995. 
BARTHE, Yannick et alii. Sociologie pragmatique: mode d'emploi. Politix, v. 103, n. 3, p. 175-204, 2013.

BEUSCART, Jean-Samuel; PEERBAYE, Ashveen. Histoires de dispositifs. Terrains et Travaux, v. 2, n. 11, p. 3-15. 2006.

BOLTANSKI, LuC; CHIAPELLO, Ève. Le nouvel esprit du capitalisme. Paris: Gallimard, 1999.

BOLTANSKI, LUC; THÉVENOT, Laurent. De la justification. Les économies de la grandeur. Paris: Gallimard, 1991.

BOWEN, John R. et alii (Dir.). European States and their muslim citizens: the impact of institutions on perceptions and boundaries. New York: Cambridge University Press, 2014.

CALLON, Michel. Éléments pour une sociologie de la traduction. La domestication des coquilles Saint-Jacques et des marins-pêcheurs dans la baie de Saint-Brieuc. L’Année Sociologique, n. 36, p. 169-208, 1986.

CALLON, Michel; MUNIESA, Fabien. Les marchés économiques comme dispositifs collectifs de calcul. Réseaux, n. 122-6, p. 189-233, 2003.

CHATEAURAYNAUD, Francis. L'épreuve du tangible. Expériences de l'enquête et surgissements de la preuve. In: KARSENTI, Bruno; QUÉRÉ, Louis (Eds.). La croyance et l'enquête: aux sources du pragmatisme, p. 167-194. Collection "Raisons pratiques". Paris: Éditions de l’Ehess, 2004.

COMAROFF, John L.; ROBERTS, Simon. Rules and processes: the cultural logic of dispute in an African context. Chicago: University of Chicago Press, 1981.

CONEIN, Bernard; DODIER, Nicolas; THÉVENOT, Laurent (Dirs.). Les objets dans l'action. De la maison au laboratoire. Paris: Éditions de l'Ehess, 1993.

COSANDEY, Fanny. Le rang. Hiérarchies d'Ancien Régime. Paris: Gallimard, 2016.

DELEUZE, Gilles. Qu'est-ce qu'un dispositif? In: Michel Foucault philosophe. Rencontre internationale, p. 185-195. Paris: Seuil, 1989.

DESROSIÈRES, Alain. La politique des grands nombres. Histoire de la raison statistique. Paris: La Découverte, 1993.

DODIER, Nicolas. Transformations des langages et du travail critique des sciences sociales. Quelques propositions à partir de l'exemple des questions médicales. Raisons Politiques, v. 55, n. 3, p. 7-46, 2014. 
_ L'espace et le mouvement du sens critique. Annales. Histoire, Sciences Sociales, v. 60, n. 1, p. 7-31, 2005.

. Leçons politiques de l'épidémie de Sida. Paris, Éditions de l'Ehess, 2003.

_. Les hommes et les machines. La conscience collective dans les sociétés technicisées. Paris: Métailié, 1995.

—_ . L'expertise médicale. Essai de sociologie sur l'exercice du jugement. Paris: Métailié, 1993.

DODIER, Nicolas; BARBOT, Janine. Autonomy and objectivity as political operators in the medical world: twenty years of public controversy about aids treatments in France. Science in Context, v. 21, n. 3, p. 403-434, 2008.

DUPRET, Baudouin. Au nom de quel droit. Paris: Msh/Lgdj, 2000.

ENGUÉLÉGUÉLÉ, Stéphane. Les politiques pénales, 1958-1995. Paris: L'Harmattan, 1989.

EWALD, François. L'État providence. Paris: Grasset, 1986.

EYMARD-DUVERNAY, François; MARCHAL, Emmanuelle. Les règles en action : entre une organisation et ses usagers. Revue Française de Sociologie, v. 35, n. 1, p. 5-36 1994.

FAVEREAU, Olivier. Organisation et marché. Revue Française d'Économie, v. 4, n. 1, p. 65-96, 1989.

FORNEL, Michel de; VERDIER, Maud. Aux prises avec la douleur. Analyse conversationnelle des consultations d'analgésie. Paris: Éditions de l'Ehess, 2014.

FOUCAULT, Michel. Le jeu de Michel Foucault. Dits et écrits, 1954-1988. t. III, 19761979. DEFERT, D.; EWALD, F. (Eds.). "Collection Quarto". Paris: Gallimard, 2001.

— Surveiller et punir. Naissance de la prison. Paris: Gallimard, 1975.

GIBSON, James J. The ecological approach to visual perception. Boston: Houghton Mifflin, 1979.

GLASER, Barney G.; STRAUSS, Anselm L. The discovery of grounded theory: strategies for qualitative research. New York: Aldine de Gruyter, 1967.

GROS, Frédéric. Les quatre foyers de sens de la peine. In: GARAPON, A.; GROS, F.; PECH, T. Et ce sera justice. Punir en démocratie, p. 13-138. Paris: Odile Jacob, 2001. 
GUILLARME, Bertrand. Penser la peine. Paris: Presses Universitaires de France, 2003.

HENDERSON, Lynne. The wrong's of victim's rights. Stanford Law Review, v. 37, n. 4, p. 937-1021, 1985.

ION, Jacques. Institutions et dispositifs. In: ION, Jacques (Dir.). Travail social en débat(s), p. 71-85. Paris: La Découverte, 2005.

KARPIK, Lucien. Dispositifs de confiance et engagements crédibles. Sociologie $d u$ Travail, v. 38, n. 4, p. 527-550, 1996.

L'économie de la qualité. Revue Française de Sociologie, v. 30, n. 2, p. 187210, 1989.

LAMONT, Michèle. La morale et l'argent. Les valeurs des cadres en France et aux États-Unis. Paris: Métailié, 1995 [1992].

LAMONT, Michèle; THÉVENOT, Laurent. Introduction: Toward A Renewed Comparative Cultural Sociology. In: LAMONT, M.; THÉVENOT, L. (Dir.). Rethinking comparative cultural sociology: repertoires of evaluation in France and the United States, p. 1-24. Cambridge: Cambridge University Press, 2000.

LASCOUMES, Pierre; BEZES, Philippe. Les formes de jugement du politique. Principes moraux, príncipes d'action et registre légal. L'Année Sociologique, v. 59, n. 1, p. 109-147, 2009.

LASCOUMES, Pierre; LE GALÈS, Patrick. L'action publique saisie par ses instruments. In: LASCOUMES, P.; LE GALÈS, P. (Dir.). Gouverner par les instruments, p. 11-44. Paris: Presses de Sciences Po, 2004.

LASCOUMES, Pierre; PONCELA, Pierrette; LENOËL, Pierre. Au nom de l'ordre. Une histoire politique du code pénal. Paris: Hachette, 1989.

LATTÉ, Stéphane. Les "victimes". La formation d'une catégorie sociale improbable et ses usages dans l'action collective. Thèse (Doctorat en Sciences Politiques) - École des Hautes Études en Sciences Sociales, Paris, 2008.

LATOUR, Bruno. La science en action. Paris: La Découverte, 1989 [1987].

. Les "vues" de l'esprit. Une introduction à l'anthropologie des sciences et des techniques. Culture Technique, v. 14, p. 6-29, 1985.

Les microbes. Guerre et paix, suivi de irréductions. Paris: Métailié, 1984. 
LICOPPE, Christian. Dans le "carré de l'activité". Perspectives internationales sur le travail et l'activité. Sociologie du Travail, v. 50, n. 3, p. 287-302, 2008.

LINHARDT, Dominique. L'économie du soupçon. Une contribution pragmatique à la sociologie de la menace. Genèses, v. 44, n. 3, p. 76-98, 2001.

NAEPELS, Michel. L'épiement sans trêve et la curiosité de tout. L'Homme, n. 203204, p. 77-102, 2012.

PEETERS, Hugues; CHARLIER, Philippe. Contributions à une théorie du dispositif. Hermès, v. 25, n. 3, p. 15-23, 1999.

REVET, Sandrine; LANGUMIER, Julien (Dir.). Le gouvernement des catastrophes. Paris: Karthala, 2013

SILVA-CASTAÑEDA, Laura. Revisiter le concept de dispositif. À partir d'un dialogue entre la sociologie pragmatique et la pensée foucaldienne. Revue de l'Institut de Sociologie, p. 91-107, 2012.

SUCHMAN, Lucy A. Plans and situated actions: the problem of human-machine communication. Cambridge: Cambridge University Press, 1987.

SWIDLER, Ann. Culture in action: symbols and strategies. American Sociological Review, v. 51, n. 2, p. 273-286, 1986.

THÉVENOT, Laurent. L'action au pluriel. Sociologie des régimes d'engagement. Paris: La Découverte, 2006.

— . Le régime de familiarité. Des choses en personne. Genèses, v. 17, n. 1, p. 72-101, 1994.

. Les investissements de forme. Cahiers du Centre d'Études de l'Emploi, n. 29, p. 21-72, 1986.

TILLY, Charles. Les origines du répertoire de l'action collective contemporaine en France et en Grande-Bretagne. Vingtième Siècle, v. 4, n. 1, p. 89-108, 1984.

WELLER, Jean-Marc. Pourquoi parler de "dispositifs"? Le cas d'un centre d'accueil de personnes séropositives. In: BOUSSARD, V.; MAUGERI, S. (Dirs.). Du politique dans les organisations. Sociologies des dispositifs de gestion, p. 249-262. Paris: L'Harmattan, 2003.

ZELIZER, Viviana A. Pricing the priceless child: the changing social value of children. New York: Basic Books, 1985. 
. Morals and markets: the development of life insurance in the United States. New York: Columbia University Press, 1979. 